\title{
Disadvantages of the Replacement Ratio Indicator with Calculation of a New Variant of This Indicator: A Case Study of Czech Republic
}

\author{
Vladimir Stipek (PhD Student) \\ University of Economics in Prague, Faculty of Economics, Czech Republic
}

Doi: 10.19044/esj.2018.v14n1p62 其L:http://dx.doi.org/10.19044/esj.2018.v14n1p62

\begin{abstract}
This article deals with the analysis of the replacement ratio (an indicator of the relation between the average wage and the average pension). This was carried out on the basis of the analysis of pensioners' consumer baskets and their expenditures. It proposes a more appropriate concept of the so-called real replacement ratio. The replacement ratio is often used for longterm (intergenerational) comparisons of the standard of living of pensioners. Also, the weaknesses of this indicator make such comparisons insufficiently informative. On the other hand, the so-called real replacement ratio takes into account the impact of significant cost items and cost items whose price is rising. As a result, this provides only a comparable standard of living without contributing to the improvement of living standards, for example through consumption expenditures. Examples of these significant cost items are housing, healthcare or transport. As illustrated by the paper, before 1989, the level of these costs was considerably lower, which is not taken into account by the average values of the non-adjusted replacement ratio. The replacement ratio calculated in the usual manner was $41.56 \%$ in 2016 and decreased to $33.7 \%$ with the use of the real replacement ratio concept.
\end{abstract}

Keywords: Replacement ratio, Pension system, Consumption expenditures, Cost of living

\section{Introduction}

To illustrate the development of people's income after retiring from active economic life, pension systems generally use the so-called replacement ratio. This can illustrate how the standard of living develops after retirement, whether it is a pension provided by an interim or funded scheme or a combination of any other systems. This replacement ratio is also used to compare the life situation of retired people over the long term, e.g. between different generations. This article responds to problems arising from an 
attempt to characterize the situation of pensioners on the basis of the replacement ratio and to draw conclusions from it.

The aim of this article is to design a new concept, which would describe the changes and would not be as static as the existing replacement ratio. This is achieved by analysing the consumer basket (basket of goods) of people in the post-productive age. The new concept, which is in the form of the so-called real replacement ratio, responds to the fact that some vital costs that define the standard of living can increase without the rising costs leading to an increase in quality of life. At the same time, with the rising costs, the available budget for current consumer spending decreases.

\section{I.}

\section{The Replacement Ratio Principle}

The Replacement Ratio is crucial for evaluating and studying all pensions systems around the world. Its policy maker is willing to make some parametric changes or a whole reform. Therefore, it is necessary to measure its impact on pensioners and their living standard. This impact, therefore, is worth evaluating e.g. during pension reform in Albania (Hado, Koxhaj, \& Metalla, 2015) or even in Kenya (Victoria Olukuru, 2014).

The predominant way of assessing the relationship between income in active life and income in post-active life is to compare the average gross monthly wages with the average pension. It is not only average values that may be used; medians can also be measured. Furthermore, there are other settings such as selecting certain age groups, for example comparing 65-74 year-olds against 50-59 year-olds, as shown in the chart below.

Chart No. 1.

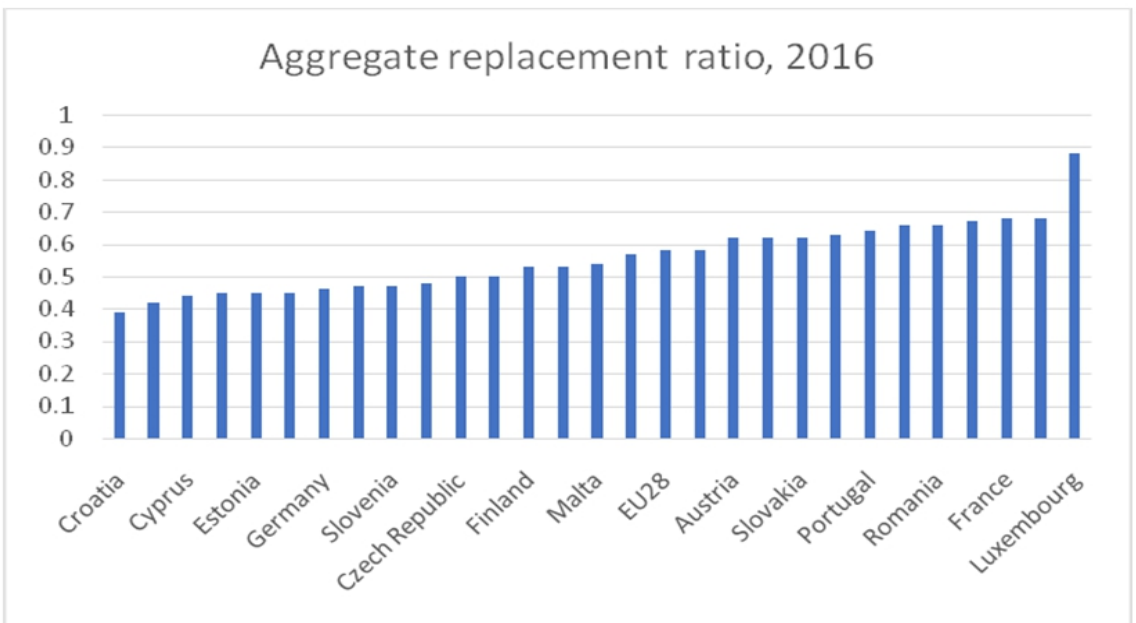

Source: Eurostat (2016). Pension Statistics - Data of Aggregate replacement ratio, 2016. 
The replacement ratio indicator does not look back at the past to compare past contributions to the system, but shows the current level of income of economically active people compared to the current level of income of post-productive citizens.

Nevertheless, a dynamic viewpoint can be implemented in this otherwise static indicator - for example, by estimating the replacement ratio at the estimated wages growth. Therefore, the chart below shows an estimate of the replacement ratio development when wages rise at the rates of 0.5 and $2 \%$.

Chart No. 2.

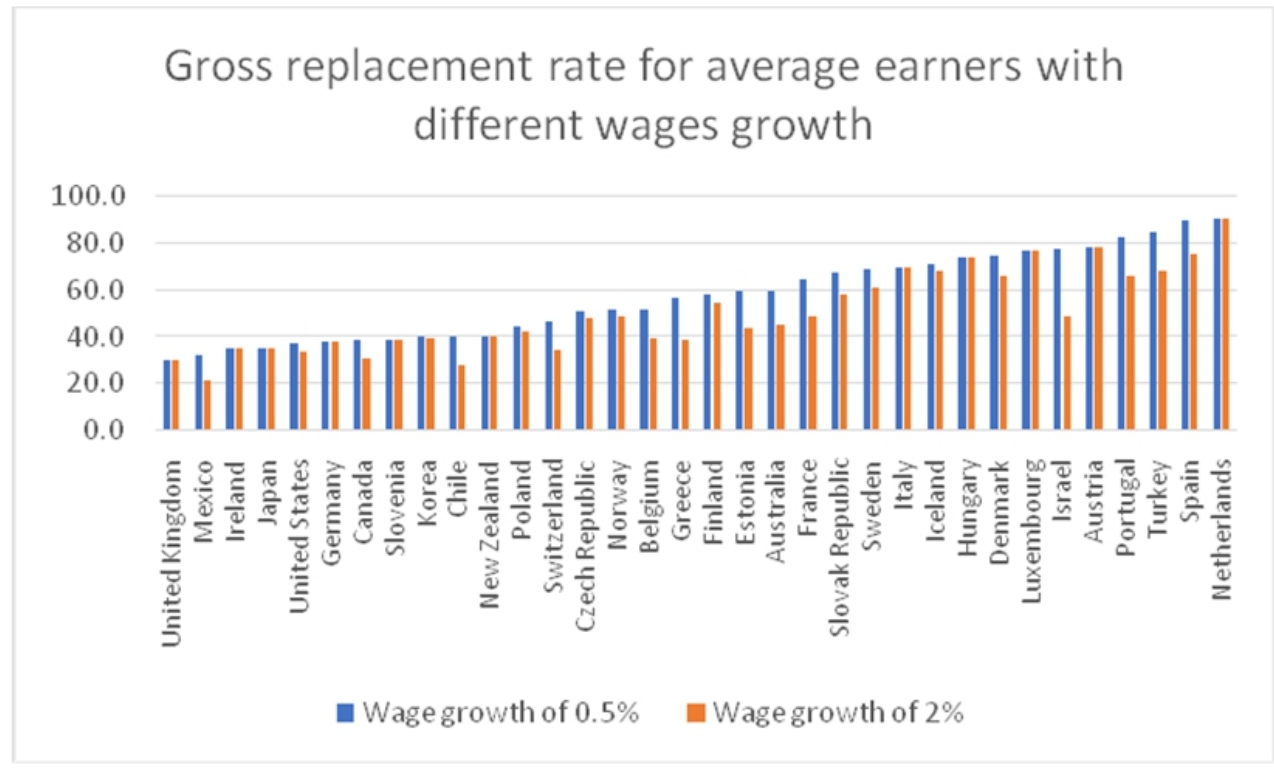

Source: OECD Statistics (2015). Pensions At a Glance 2015, page 115

Replacement ratios calculated for specific years are used to assess whether and how people's living standards change over time. However, this is not satisfactory because the average income and pension figures do not reflect real life costs. Therefore, it is necessary to introduce a so-called real replacement ratio, which would reflect not only the relation of the average quantities, but also the changes in consumer prices and the transformation of the consumer basket of the social groups concerned.

The so-called replacement ratio has deficiencies that limit its informative value. Average wages indicate long-term average earning of a working person, but they do not inform us of the structure of needs that are satisfied based on this income. They also do not say anything about how the price of satisfying the basic needs of a particular population is developing. 
Chart No. 3.

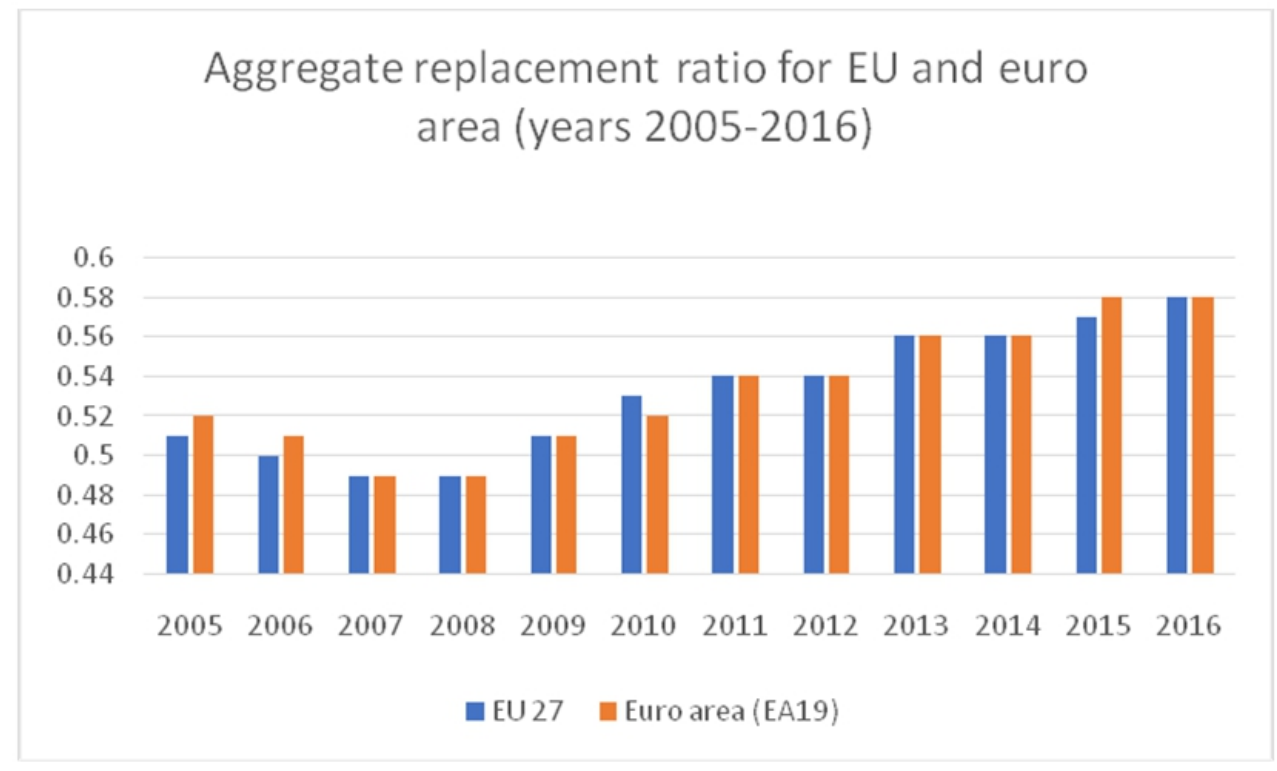

Source: OECD, Pensions at a Glance 2015, page 115

\section{Introducing the So-called Real Replacement Ratio}

This paper reacts to the established term of the replacement ratio by introducing the author's own indicator - the so-called real replacement ratio. The structure of this indicator should better reflect a realistic compensation for the cost of living for pensioners.

At different times, people in post-productive age face different prices and, above all, the change of the consumer basket. Over time, housing, for example, can change from a relatively affordable service into a relatively expensive part of the consumer basket. People in active age do not face the same consumption costs as pensioners. To compare pensions and wages, we need to take these differences into account. The Real Replacement Ratio (RRR) can be written as follows:

$R R R=\frac{\text { average pension } * \text { insignificantincrease/decreasein price of a consumer basket item }}{\text { average wages }}$

The concept of a real replacement ratio requires some factors in the very complex area of housing, healthcare, and transport to be toned down, while others are highlighted and used, in particular the cost area, the area of pricing or access to the market.

The concept of a real replacement ratio is a legitimate tool of analysis because previous concepts (i.e. replacement ratio in the form of average gross monthly wages compared to average pension) fail or do not have sufficient informative value. 
The real replacement ratio is suitable for comparing incomes of economically productive and post-productive people from different generations. For instance, over the course of one decade, the changes are not so significant that, for example, a change in consumer behaviour would be visible. While new technologies have appeared over the years and some products and services have disappeared due to technological progress, on average, the expenditures in different spending sectors are not different. In addition to the price and the emergence of new products and services, the trendiness and popularity of certain expenditures is also an important factor - on average. However, expenditures which belongs to a particular sector (such as cultural expenditures, household equipment) and households are not willing to change the spending structure dramatically.

The following chart illustrates the comparison of the household consumption expenditure structure of pensioners. In some cases, there are relatively significant changes; however if the system is stable, there are no major structural changes in an approximately 10-year horizon. In 1989, a change of the entire economic system took place in the Czech Republic. As a result, there is a greater difference between 1989 (which to a certain extent still represents the previous economic system) and the present situation in 2016. It is also clear from the chart that the informative value of the real replacement ratio lies above all in an intergenerational comparison spanning over several decades.

Chart No. 4.

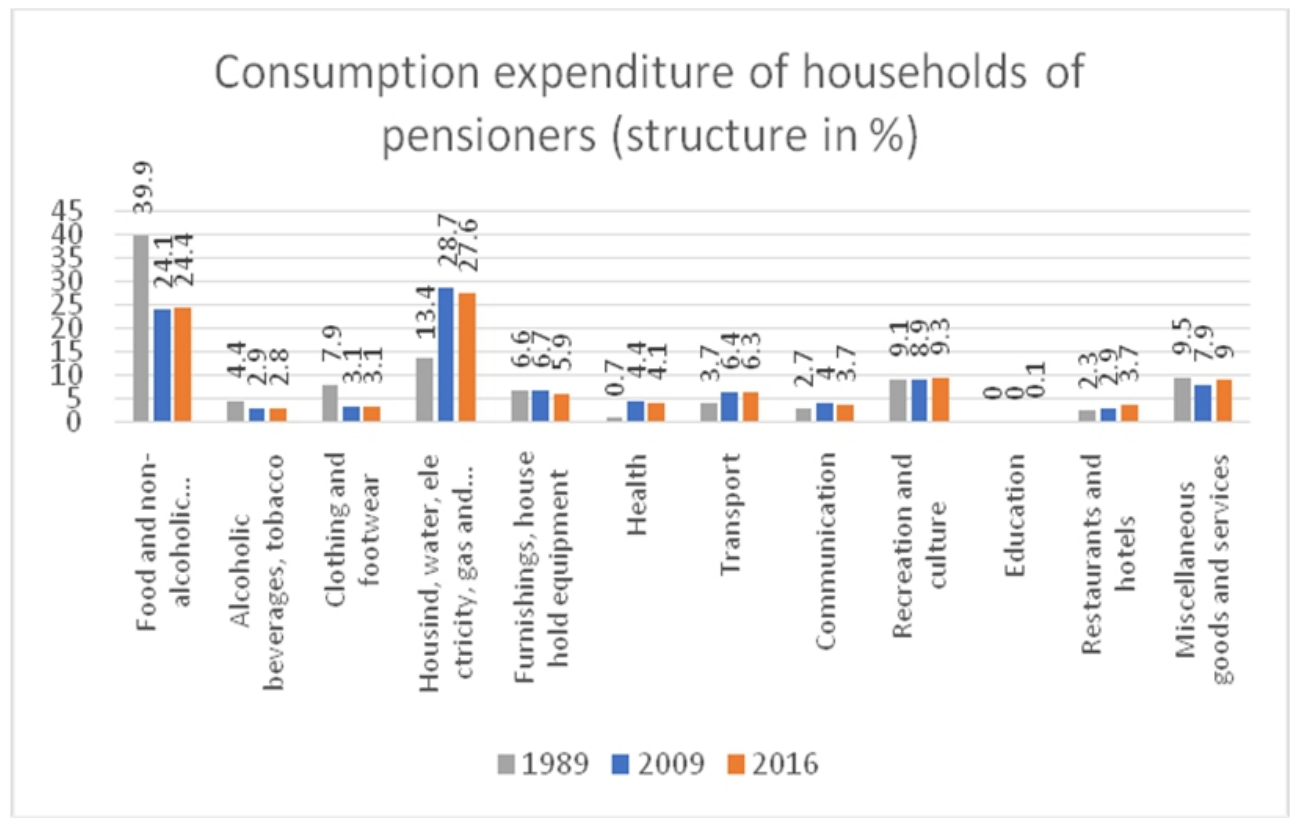

Source: Household Budget Survey of the Czech Statistical Office (CSO). Note: pensioners here designate people over 70 years of age and economically inactive household members 
However, the concept of a real replacement ratio suffers from some other limitations - it depends on a subjective opinion about what consumer basket will be included in the calculation. The real replacement ratio is a crosssectional variable, which nevertheless does not take into account the diversity of individual consumer baskets, but it instead unifies them in monetary terms. Based on the fact it works with average values, it depends greatly on how we define the areas to be covered by the replacement ratio. It works with a subjective view of what would be included in the consumer basket, dealing not just with the demand side, that is what the seniors consume and use, but also with the supply side, in the sense of whether the government is able to influence the prices of the goods or services in question.

In the denominator, there is the average wage that is not adjusted. This is because the average wage is illustrated in this case by a wide range of disciplines and social groups, and there is no need for adjustment. In case of pension, the group receiving this benefit is a very homogeneous category of people. The average wage is a sufficiently cross-sectional indicator that is not necessary to adjust.

Changes in consumer habits and the changing nature of products, goods and services complicates long-term comparisons. Nevertheless, it would be possible to identify several spending areas where development has occurred and where the impact on pensions can be traced.

First, we must eliminate common consumer expenditures from these areas - because of the changes in consumer habits and a qualitative leap in commercially available technologies.

Consequently, the choice of "goods" that are included in the concept of a real replacement ratio must be a combination of what senior citizens use and what the state authority can influence - in order to increase the real replacement ratio - for example by providing pensioners with goods that would enable them to direct a part of their retirement funds away from healthcare, transport, and housing to other consumer areas. For this reasons, the areas of transport, health care and housing are very important. Social services have been selected for the purpose of this paper. However, efforts to influence these areas present, apart from social services, an intervention in a freely functioning market. Social services are a young industry that would have been almost unprofitable without state support. The fields of transport, health and housing are different - these are areas from which the government has gradually withdrawn, but still holds a significant share in them, and has a major impact on their functioning.

When looking at historical developments, it appears that the biggest changes in the consumer basket have occurred in housing and healthcare. Consumer spending is complicated in that it is necessary to generalize it for the entire economically active group of people. However, this is difficult 
because among the economically active people, we can find young people who are establishing their households, as well as people in the second half of active life, whose households have already been furnished and perhaps they support their children. Consumer spending is to some extent a typical variable cost that can be lowered or regrouped. The costs of housing and healthcare are mostly of a fixed nature. The costs in the field of transport are also fixed to some extent, as economically active people have to commute for work. In addition, older people have to commute, for example, to do their shopping or use medical facilities.

Another problem is that, given the unavailability of some services, the comparison of, for example, healthcare quality is limited. Before 1989, spa care was widely available as part of healthcare, and it was mostly provided to sick working people and pensioners free of charge. At present, however, spa care is not part of the standard treatment. As a result, a long-term intergenerational comparison must address this issue.

\section{Concept of Real Replacement Ratio Applied on the Case Study of the Czech Republic}

It is clear that the pensioner's consumer basket changes (for example, the prolonged life expectancy means that a higher portion of pensioners is older and has other needs than the newly retired pensioners) as do the costs of satisfying the pensioner's needs. It also depends on the specific conditions of individual pensioners - very often, however, these are similar life situations - when a senior citizen is threatened by poverty.

The following chart shows a long-term comparison of the real replacement ratio. The nature of the socialist economic system, including a lower life expectancy, gave the pensioners certain advantages - the healthcare system was at a lower level compared to the current reality of the Czech Republic. However, it was fully free of charge, and housing was highly subsidized by the state. People mostly got housing during their working career (i.e. business and corporate dwellings provided by businesses), often acquired ownership rights to it (after a certain period of time or at a low so-called residual price), or paid very low rent, which was a fraction of value that the tenants would have to pay to cover the government's investments in the housing fund. Similarly, power sources were fully in the hands of the government - the state controlled the extraction of raw materials, electricity and heat production or received them cheaply from fellow countries of the Council for Mutual Economic Assistance (natural gas and oil). Before 1989, pensioners retained a larger portion of their pension for consumption expenditures. Intergenerational comparison is however problematic because the structure of consumption expenditures is completely different - ordinary 
products have very different quality and price levels, and seemingly identical products or goods might be difficult to compare.

Chart No. 5. Long-term replacement ratio timeline (in \%)

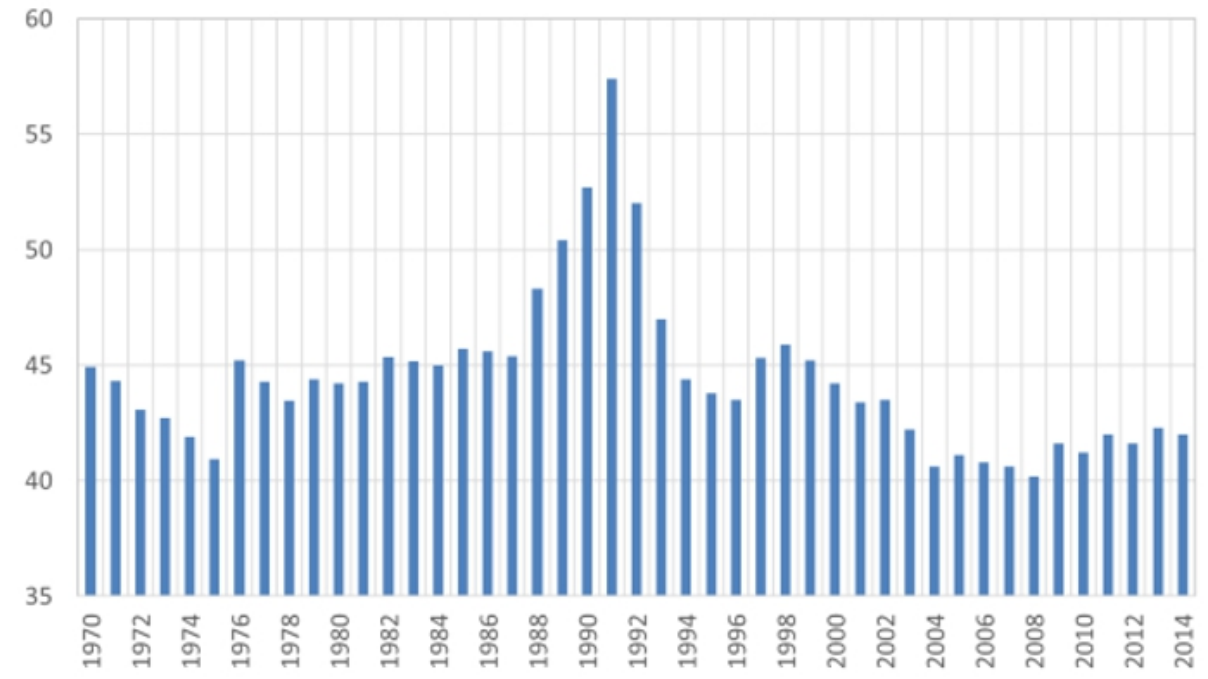

Source: Retirement Commission, Proposals for the Valuation of Pensions, June 2, 2016

It is clear from the chart that the replacement ratio at the time of socialism was higher than at present. Before 1989, the replacement ratio was about $45 \%$, but instabilities of the socialist economy during the oil shocks (around 1973) led to its decrease. This is because at that time, prices of selected items increased, salaries in more efficient fields were growing, and naturally there was a nominal stagnation of pensions. Subsequent efforts to periodically valorisation and stabilization of the economy led to anchoring the replacement ratio at 45\%. After 1989, with the disintegration of socialism and the emergence of market economy, various fluctuations occurred, prices underwent liberalization, and there was a steep increase in the prices of certain goods. Wages and salaries, as well as pensions, grew inconsistently and often randomly; in the case of wages, this happened according to the principles of the market economy, which illustrated the transformation process. Subsequently, the replacement ratio stabilized slightly above $40 \%$. However, this indicator is the basic ratio of the average values - the average pension and the average wage. It does not tell us much about real money balances, and hence the quality of the life of pensioners.

As mentioned above, we cannot carry out an intergenerational comparison of the consumption expenditures in which there are changes in consumer preferences and major technological developments. Today's products, which appear to satisfy the same needs as similar products $40-50$ years ago, already have a different character and also the demand for them is 
quite elastic. It is more fitting to describe the present situation as a new market, with new preferences and entirely new products.

\section{Healthcare}

Over the years, other systems interconnected with the pension systems have also been subject to change. Comparing, for example, the current replacement ratio with the replacement ratio before 1989 is complicated. This is because at that time, there was also a very different healthcare system that did not require such a high degree of patient involvement.

In 1989, healthcare expenditures amounted to $0.7 \%$ of pensioners' income, while now this value is above 4\%. However, expenditures before 1989 do not include what was provided fully free of charge and is not part of the government healthcare expenditures at present. This does not concern just spa care, which is currently de facto not provided in the Czech Republic (only on a private basis). It does not also concern preventive care, which is now a private initiative of individual citizens, and is not a free benefit provided to the entire population.

\section{Housing}

The CSO data show that in 1989, housing costs were at $13.4 \%$ of pensioners' total expenditures, while currently they have exceeded $27 \%$. Between 1989 and 1995, the housing expenditure component has increased from the level of $13 \%$ to $21 \%$. "The highest increase in the share of final consumption expenditures was recorded in housing expenditures - from $21 \%$ in 1995 to $27 \%$ in 2015. Housing expenditure includes rent (actually paid and imputed) and expenses related to the operation and routine maintenance of dwellings." (CSO, 2016; Household consumption has increased by two-thirds in twenty years, Statistics \& Us, 2016/7-8)

According to the CSO, average expenditures per person and month in 2015 belonging to the group (according to COICOP classification) Rent and Housing Services amounted to CZK 4,511. These figures, however, are calculated for an "average individual", not specifically for pensioners who have more opportunities, time and motivation to reduce these costs effectively.

Consumption expenditures of pensioners according to the CSO data (household balance statistics) for the 4th quarter of 2015 amounted to CZK 10,868, of which CZK 2,878 was allocated to "housing, water, energy, fuel"; also, the sub-component "Electric and thermal energy, gas, fuel" amounted to CZK 1,642 (CSO, 2014; Household Budget statistics).

A long-term view of housing costs (CSO, 2004) shows that housing costs are growing at a slower pace than the rise in pensioners' incomes (pensions), but they still account for a considerable amount of CZK 2,812 per month. It is important to answer why, in the case of data for a specific group 
represented by pensioners, housing costs are not as high as the average housing costs of inhabitants of the Czech Republic. This is because pensioners can resolve their individual situation by, for example, moving to a cheaper location or a smaller real estate (apartment). It should also be borne in mind that pensioners in the Czech Republic are very often property owners. They either live in stand-alone houses or in an apartment owned by them before 1989, or they have subsequently bought it from a business or the town/city. Real estate acquisition through mortgage debt instruments has also been completed by a number of current pensioners, as people in pre-retirement age usually have higher incomes and savings that allow them to fully redeem the mortgage by the time they begin their retirement. It is also common for people to prepare for their retirement in the sense that they carry out housing renovations during their economically active life. This leads to the fact that aggregate housing costs may be relatively low (people live in less expensive real estate, are owners of real estate, have invested in real estate at the time of economically active life, etc.).

\section{Transport}

One cost item that actually influences the quality of life of pensioners is the cost of (mainly) domestic and urban transport. If we compare the current situation with that before 1989, transport costs constituted a negligible portion of the consumer basket, as domestic and urban transport was subsidized, and was in addition implemented in a non-market economic system. The resulting low prices were caused by the availability of fuel and energy feedstock imported at low prices. Although at present, for example, annual tickets for the elderly in large and small towns of the Czech Republic are mostly discounted, as one-off payment and they represent a relatively high portion of one monthly pension. To illustrate the state economic costs of a free fare for seniors, Slovakia can be used as an example (Office of the Government of the Czech Rep., 2016; Information on the introduction of economic, financial and social package (free travel) in rail transport). The Slovak Prime Minister Robert Fico's government, under the so-called financial, economic and social package, introduced free travel by rail for selected categories of passengers on the territory of the Slovak Republic on October 22, 2014 with effect from November 17, 2014 (Office of the Government of the Czech Rep., 2016). The aim of this measure is to support further regional development of the SR and to follow the EU in the use of greener and safer transport.

Therefore, free travel by train is provided to the following categories of passengers when traveling in class 2: children under 15; daytime students under 26; persons above age 62 (seniors over 62 do not have to register to obtain the card; they only have to show their ID when purchasing zero-valued tickets); persons receiving an invalidity or orphan's pension. The above 
applies not only to citizens of the Slovak Republic, but also to the inhabitants of all EU Member States traveling on the territory of the Slovak Republic. Citizens of non-EU countries permanently residing in the EU are also eligible. Free transport applies to all state-subsidized train routes - these only include trains that are in the so-called public service obligation (i.e. interurban and regional lines operated also by private carriers on key lines). The Ministry of Transport of the Slovak Republic estimated that this measure would cost at least EUR 13 million per year, with the real cost being even higher. Nevertheless, it is also necessary to take into account the benefits in the form of widely available public transport.

Now we can try to calculate the real replacement rate using the data of 2016.

The average old-age pension in the reference year 2016 was CZK 11,640 (Czech Social Security Administration, 2016) and the average wage in same year was CZK 27,575 (CSO, 2016; Wages, Labor Costs data), representing a replacement rate of $41.56 \%$.

However, the real replacement rate should take into account the abovementioned changed and, at the same time, comparable costs in the areas of housing, health, and transport.

Between 1989 and 2016, the change in the cost of housing was reflected by an increase of an average retirement expenditure by $14.2 \%$. In the healthcare sector, the increase in the same period was by $3.4 \%$ and in the transport sector by $2.6 \%$.

At the same time, there was a reduction in the average expenditure share in comparable areas with the cost of clothing and footwear declining by $4.8 \%$ and food costs declining by $15.5 \%$ - however, consumer expenditure declined not only thanks to the affordability of clothing and the reduction in the price of groceries, but primarily, it was a reduction in the expenditure share forced by rising costs of housing or healthcare.

The replacement ratio thus declined from $41.56 \%$ to $33.7 \%$ due to the increase in the necessary costs (i.e. housing, healthcare, transport). Thus, this should better illustrate the real income situation of pensioners in the Czech Republic.

\section{Conclusion}

As can be seen from this article, the current and widely used real replacement ratio is not ideal for long-term comparisons, when changes occur to consumer habits, lifestyle, and often the entire economic system. The replacement ratio is intended to show the relation between the average wage of the economically active population and the incomes of the economically post-productive population. Thus, comparability of the average items of different time periods presents a challenge. 
Some expenditure items of pensioner households may develop over time to become more significant without increasing the quality of life - in particular, housing or transport costs. Thus, the replacement ratio, for example, when compared intergenerationally, will not be indicative. This is because certain part of the pension may be subtracted by an expenditure item that, for example, ceases to be subsidized, which retracts part of the pension at the expense of consumption.

The real replacement rate thus provides an "adjusted" assessment of how the replacement ratio has changed over time. If some components do not take the form of voluntary consumption, but rather represent necessary expenditures for maintaining the current life standard, they should not be perceived as an actual part of the available income. For the Czech Republic, it is typical that before 1989, some basic living costs of pensioners were relatively smaller, e.g. housing costs, health care costs or transport costs. These costs also had a different form, and pensioners could benefit from a range of public services that are currently unavailable to them. Simple monetary comparison does not take into account the real situation of pensioners and their disposable income.

The specific results, according to the analysis of the expenditure structure of post-productive people in 2016 and in 1989, show a rise in costs, especially in the area of housing. The replacement ratio found using the classical method was $41.56 \%$ in 2016 and decreased to $33.7 \%$ after adjustment (i.e. the increase in necessary expenditures to ensure the same living conditions as in 1989 in the area of housing, health and transport). This shows that a long-term comparison based on average values is not the best method, and we need to supplement it by, for example, using the real replacement rate defined in this article.

\section{References:}

1. Eurostat. (2017). Data - Aggregate Replacement ratio, Pension Statistics. Eurostat, European Commission. Retrieved fromhttp://ec.europa.eu/eurostat/tgm/table.do?tab=table\&plugin=1\&1 anguage $=$ en $\&$ pcode $=$ tespm 100

2. OECD.(2015). Pensions at a Glance 2015: OECD and G20 indicators, OECD Publishing, Paris. Retrieved from http://dx.doi.org/10.1787/pension_glance-2015-en

3. OECD.(2017). Pensions at a Glance 2017: OECD and G20 Indicators, OECD Publishing, Paris. Retrieved fromhttp://dx.doi.org/10.1787/pension_glance-2017-en

4. Ministry of Labour and Social Affairs. (2015): The Concept of Social Housing of the Czech Republic 2015-2025, law proposal. Government 
of the Czech Republic - Ministry of Labour and Social Affairs. Source: Legislative Evidence System of Czech Rep.

5. Government Retirement Commission. (2016). Proposals for the Valuation of Pensions, June 2, 2016. Government Retirement Commission - Expert Panel on Pension Reform/Expert Committee on Pension Reform, Czech Republic. Prague. Retrieved fromhttp://www.duchodova-komise.cz/

6. Czech Statistical Office. (2016). Household consumption has increased by two-thirds in twenty years - article. Statistical overview (magazine), Statistics \& Us, Edition 2016/7-8. Prague.

7. Czech Statistical Office.(2014). Household Budget Statistics, 4th quarter 2015, Cash expenditure - average per person in CZK per month. Prague. Czech Statistical Office Data.

8. Czech Statistical Office.(2004). Household Budget Statistics, 4th quarter 2015, Selected cash expenditure items from 1989 to 2003.Prague. Czech Statistical Office Data.

9. Czech Statistical Office. (2016).Household Budget Statistics, Households by age of the head of household - Consumer Expenditure Groups - Average per person in CZK per year, structure in \%.Prague. Czech Statistical Office Data.

10. Office of Government of the Czech Republic. (2016). Information on the introduction of economic, financial and social package (free travel) in rail transport for selected categories of passengers in Slovakia. 2016. without ISBN, Prague, Analysis Department - Office of Government of the Czech Rep.

11. Czech Social Security Administration. (2016). Average solo of pensions - data of December 31, 2016. Prague, Czech Social Security Administration Data.

12. Czech Statistical Office. (2016).Wages, Labour Costs - time series, average gross monthly wage, preliminary data for 2016.Prague. Czech Statistical Office Data.

13. Hado, A., \& Koxhaj, A., \&Metalla, O. (2015). Reformation of the pension scheme in Albania. European Scientific Journal: edition vol. 11, October 2015. ISSN: 1857-7431.

14. Victoria, M.,\& Olukuru, J. (2014). Impact of pensions reforms on the Kenyan pension industry. European Scientific Journal: Special edition, August 2014. ISSN: 1875-7431. 